\title{
Correction to: Fractures in untreated patients with osteoporosis in Germany: an InGef healthcare insurance database analysis
}

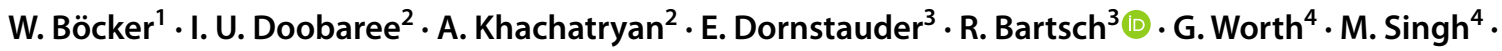 \\ D. A. Kahangire ${ }^{4}$
}

Published online: 1 December 2021

( ) International Osteoporosis Foundation and National Osteoporosis Foundation 2021

\section{Correction to: Osteoporos Int https://doi.org/10.1007/s00198-021-06051-w}

In this article, the author name Indraraj Umesh Doobaree was incorrectly written as Indraraj Umesh Doobare.

The original article has been corrected.

Publisher's note Springer Nature remains neutral with regard to jurisdictional claims in published maps and institutional affiliations.

The original article can be found online at https://doi.org/10.1007/ s00198-021-06051-w.

Robert Bartsch

rbartsch@amgen.com

1 Department of General, Trauma and Reconstructive Surgery,

Munich University Hospitals, Ludwig-Maximilians-

University, Munich, Germany

2 Certara - Evidence \& Access (Analytica LASER), London, UK

3 Amgen, München, Germany

4 Amgen (Europe) GmBH, Roktreuz, Switzerland 